Note

\title{
Effects of Citric Acid and Lemon Juice on Iron Absorption and Improvement of
}

\section{Anemia in Iron-Deficient Rats}

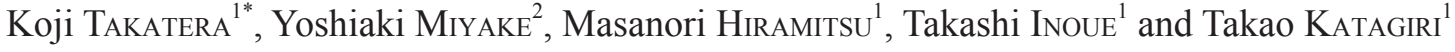 \\ ${ }^{1}$ Central Research Laboratory, Pokka Co., Ltd., 45-2 Juuniso, Kumanoshou, Kitanagoya, Aichi 481-0006, Japan \\ ${ }^{2}$ Faculty of Human Wellness, Tokaigakuen University, 2-901 Nakahira, Tenpaku-ku, Nagoya, Aichi 468-8514, Japan
}

Received May 19, 2011; Accepted October 30, 2011

We investigated the effects of citric acid and lemon juice on iron absorption and improvement of anemia in iron-deficient rats. In Expt. 1, rats were administered ferric iron solution $(2 \mathrm{mg} / \mathrm{kg})$ with various concentrations of citric acid (1-6\%) by a single oral gavage. The serum iron levels were significantly higher in rats treated with citric acid than those without citric acid. In Expt. 2, anemic rats were administered ferric iron solution (control) with $1 \%$ citric acid or diluted lemon juice containing $1 \%$ citric acid by oral gavage dose of $2 \mathrm{mg} \mathrm{Fe} \mathrm{e}^{3+} / \mathrm{kg} / \mathrm{day}$ for $20 \mathrm{~d}$. Heart weight and unsaturated iron-binding capacity (UIBC) were significantly lower in the citric acid group, whereas serum iron level and hematocrit value were significantly higher in the citric acid group than in the control group. Hemoglobin concentration was significantly higher in the citric acid group and lemon juice group. These results suggest beneficial effects of citric acid and lemon juice on iron bioavailability.

Keywords: citric acid, lemon juice, nonheme iron, iron absorption, iron-deficiency anemia

\section{Introduction}

Iron deficiency is the most common form of malnutrition in the world, affecting more than two billion people globally. Iron deficiency anemia is most prevalent and severe in young children and women of reproductive age, but it is also often found in older children, adolescents and adult men. Effective control of iron deficiency anemia may yield benefits to human health, such as decreased low birth weight, lower perinatal mortality, lower maternal mortality, improved child survival, improved fitness and improved work capacity in all individuals (Stoltzfus and Dreyfuss, 1998). In addition, dietary iron deficiency causes several health problems such as bone loss and hyperlipidemia (Katsumata et al., 2006; Ndong et al., 2007).

The amount of iron absorbed from diet is poor, and is influenced by the interplay between promoters and inhibitors of iron absorption (Bothwell et al., 1989). Therefore, fortification of suitable food vehicles with iron and/or promoters is assumed to be an effective method for improving

*To whom correspondence should be addressed.

E-mail: koji_takatera@pk.pokka.co.jp iron deficiency. Several organic acids (ascorbic, citric, malic, tartaric, or lactic acid) are known as promoters of nonheme iron absorption (Sean and Lynch, 1997). Some human studies have indicated that the addition of organic acids to meals or beverages improved iron absorption (Derman et al., 1980; Gillooly et al., 1983; Zhang et al., 2007). Since citrus fruits are particularly rich sources of organic acids, they may act as a promoter of iron absorption (Ballot et al., 1987). However, one study reported that long-term ingestion of lime juice with diets high in nonheme iron did not improve iron status in iron-deficient women (Garcia et al., 2003). In addition, there was very little information on efficacy of organic acids and citrus fruits in improving iron deficiency anemia. Therefore, this study investigated the effects of citric acid and lemon juice, which has an abundance of citric acid, on iron absorption and improvement of anemia in iron-deficient rats.

\section{Materials and Methods}

Animals and diets Five-week-old male Wistar strain rats were purchased from Japan SLC, Inc. (Hamamatsu, Japan). The rats were housed in individual stainless cages in a room with controlled temperature $\left(22 \pm 2^{\circ} \mathrm{C}\right)$, humidity (55 
$\pm 10 \%$ ), and lighting (lights on from 7:30 to 19:30). Before starting the experiments, all rats were given free access to a commercial non-purified diet (Type CE-2, CLEA Japan, Inc., Tokyo, Japan) and deionized water for $7 \mathrm{~d}$ to acclimatize them to the housing conditions. Two separate experiments were conducted in this study. In both experiments, an irondeficient diet (Type F2FeDD) purchased from Oriental Yeast Co., Ltd. (Tokyo, Japan) was used. The F2FeDD diet contained $2.3 \mathrm{ppm}$ of iron as measured with an atomic absorption spectrophotometer.

In Expt. 1, we investigated the effect of various concentrations of citric acid on the absorption of ferric iron. Rats were given free access to the F2FeDD diet for $7 \mathrm{~d}$ to induce suspected iron deficiency (Ujike et al., 2003). After the feeding for $7 \mathrm{~d}$, serum iron level and hemoglobin concentration in rats decreased from $136 \pm 12$ to $101 \pm 12 \mu \mathrm{g} / \mathrm{dL}$, and from $15.1 \pm 0.4$ to $12.1 \pm 0.3 \mathrm{~g} / \mathrm{dL}$, respectively $(p<0.05$, paired t-test). The day before the experiment, rats were fasted for $16 \mathrm{~h}$ but had free access to water. Iron-deficient rats were randomly divided into four groups of eight, and administered ferric iron solution (control group) containing 1-6\% citric acid by gavage dose of $2 \mathrm{mg} \mathrm{Fe}{ }^{3+} / \mathrm{kg}$ (the solutions were given at a volume of $5 \mathrm{~mL} / \mathrm{kg}$ ). Blood samples were collected from the tail vein at $0,20,40$ and $60 \mathrm{~min}$ after the administration, and each serum was separated by centrifugation at $3,000 \mathrm{rpm}$ for $15 \mathrm{~min}$ at $4^{\circ} \mathrm{C}$. In our preliminary experiments, serum iron levels peaked at $60 \mathrm{~min}$, and remained almost constant until 180 min after $\mathrm{Fe}^{3+}$ administrations. Therefore, the blood samples were collected during periods 0-60 min after administrations in this experiment.

In Expt. 2, we investigated the effects of citric acid or lemon juice on the improvement of anemia. Anemia was induced in rats by feeding of the F2FeDD diet for $28 \mathrm{~d}$ (Kawakami et al., 1988). On the other hand, a basal diet group was fed with the F2FeDD diet supplemented with 200 ppm iron from ferric citrate for $28 \mathrm{~d}$. After the feedings for $28 \mathrm{~d}$, hemoglobin concentration in the F2FeDD diet group was significantly lower than that in the basal diet group (7.3 \pm 0.4 vs. $19.6 \pm 0.6 \mathrm{~g} / \mathrm{dL}, p<0.01$, Student's $t$-test). Then, the anemic rats were randomly divided into four groups of five, and continued on the F2FeDD diet with administration of ferric iron solution (control group), 1\% citric acid (citric acid group), diluted lemon juice containing $1 \%$ citric acid (lemon juice group), or $\mathrm{pH}$ adjusted with hydrochloric acid ( $\mathrm{HCl}$ group) to the same $\mathrm{pH}$ as $1 \%$ citric acid $(\mathrm{pH} 2.1)$ by gavage once per day at a dosage of $2 \mathrm{mg} \mathrm{Fe} 3^{+} \mathrm{kg}$ (the solutions were given at a volume of $5 \mathrm{~mL} / \mathrm{kg}$ ) between $16: 00$ and 17:00 for $20 \mathrm{~d}$. The basal diet group was also continued on the iron supplemented diet with administration of deionized water once per day at a volume of $5 \mathrm{~mL} / \mathrm{kg}$ between 16:00 and 17:00 for $20 \mathrm{~d}$. During the experimental period, rats were allowed free access to the diets and deionized water. The lemon juice used was a commercial bottled product (Pokka Lemon 100, Pokka Co., Ltd., Nagoya, Japan) containing citric acid (65.3 g/L) and ascorbic acid (267 mg/L). At the end of the experiment, the rats were sacrificed between 9:00 and 11:00 AM without fasting. Blood sample was collected from the abdominal aorta after anesthesia with intraperitoneal injection of thiopental $(50 \mathrm{mg} / \mathrm{kg})$, and the serum was separated by centrifugation at $3,000 \mathrm{rpm}$ for $15 \mathrm{~min}$ at $4^{\circ} \mathrm{C}$. After collecting the blood sample, the heart was immediately excised and weighed. The animal experiments of this study were approved by the Laboratory Animal Care Committee of the Faculty of Human Wellness at Tokaigakuen University, and performed ethically, obeying the "Guidelines for proper conduct of animal experiments" of the Science Council of Japan.

Biochemical analysis The serum iron level and hemoglobin concentration were measured using commercial kits (Wako Pure Chemical Industries, Ltd., Osaka, Japan). The hematocrit value was determined by centrifugation at 12,000 rpm for 5 min using capillary tubes (Microhematocritcapillaries, Hirschmann Laborgeräte, Eberstadt, Germany). The unsaturated iron binding capacity (UIBC) was measured using the bathophenanthroline method (Beale et al., 1962).

Statistical analysis Statistical significance was determined using a one-way ANOVA followed by Tukey's multiple-comparison test using the JMP software program version 8.0 (SAS Institute Inc., Cary, NC, USA). Differences were considered to be significant at $p<0.05$.

\section{Results}

Effects of various concentrations of citric acid on the absorption of ferric iron (Expt. 1) When ferric iron solution with various concentrations of citric acid were administered to iron-deficient rats, the serum iron levels at 40 and $60 \mathrm{~min}$ after the administrations increased significantly in all citric acid-administered groups than in the control group (Fig. 1).

Effects of citric acid or lemon juice on the improvement of anemia (Expt. 2) As citric acid contributed to the absorption of ferric iron in Expt. 1, we subsequently investigated the effects of repeated administrations of ferric iron with citric acid or lemon juice on the improvement of anemia. The results of final body weight, food intake, relative heart weight, serum iron level, hemoglobin concentration, UIBC and hematocrit value are shown in Table 1. Except for the basal diet group, significant differences were not observed in final body weight and food intake between the other four groups. Relative heart weight and UIBC were significantly lower in the citric acid group and basal diet group than in the 
Table 1. Final body weight, food intake, relative heart weight, serum iron, hemoglobin, unsaturated iron binding capacity (UIBC) and hematocrit in anemic rats administered with ferric iron of various sample solutions.

\begin{tabular}{|c|c|c|c|c|c|c|c|}
\hline & $\begin{array}{l}\text { Final BW } \\
\text { (g) }\end{array}$ & $\begin{array}{c}\text { Food Intake } \\
\text { (g/day/rat) }\end{array}$ & $\begin{array}{l}\text { Heart Weight } \\
\text { (g/100g BW) }\end{array}$ & $\begin{array}{c}\mathrm{Fe} \\
(\mu \mathrm{g} / \mathrm{dL})\end{array}$ & $\begin{array}{l}\text { Hemoglobin } \\
\text { (g/dL) }\end{array}$ & $\begin{array}{c}\text { UIBC } \\
(\mu \mathrm{g} / \mathrm{dL})\end{array}$ & $\begin{array}{c}\text { Hematocrit } \\
(\%)\end{array}$ \\
\hline Control & $340 \pm 13^{\mathrm{a}}$ & $16.1 \pm 0.5^{\mathrm{a}}$ & $0.30 \pm 0.02^{\mathrm{a}}$ & $115 \pm 16^{\mathrm{a}}$ & $12.9 \pm 0.3^{\mathrm{a}}$ & $222 \pm 5^{\mathrm{a}}$ & $42.9 \pm 0.9^{\mathrm{a}}$ \\
\hline Citric acid & $347 \pm 8^{\mathrm{a}}$ & $16.8 \pm 0.4^{\mathrm{a}}$ & $0.28 \pm 0.04^{\mathrm{b}}$ & $172 \pm 12^{b}$ & $15.1 \pm 0.3^{b}$ & $208 \pm 3^{b}$ & $45.3 \pm 0.5^{b}$ \\
\hline Lemon juice & $342 \pm 7^{\mathrm{a}}$ & $17.1 \pm 0.6^{\mathrm{a}}$ & $0.30 \pm 0.07^{\mathrm{a}}$ & $153 \pm 21^{\mathrm{a}}$ & $15.3 \pm 0.5^{b}$ & $217 \pm 6^{\mathrm{a}}$ & $45.5 \pm 1.1^{\mathrm{a}}$ \\
\hline $\mathrm{HCl}$ & $341 \pm 11^{\mathrm{a}}$ & $16.9 \pm 0.6^{\mathrm{a}}$ & $0.30 \pm 0.09^{\mathrm{a}}$ & $131 \pm 25^{\mathrm{a}}$ & $14.3 \pm 0.6^{\mathrm{ab}}$ & $215 \pm 7^{\mathrm{a}}$ & $44.1 \pm 1.4^{\mathrm{a}}$ \\
\hline Basal & $382 \pm 8^{b}$ & $23.4 \pm 0.2^{\mathrm{b}}$ & $0.28 \pm 0.01^{\mathrm{b}}$ & $189 \pm 20^{b}$ & $19.9 \pm 0.4^{\mathrm{c}}$ & $198 \pm 3^{b}$ & $55.5 \pm 1.0^{\mathrm{c}}$ \\
\hline
\end{tabular}

Values are means $\pm \mathrm{SEM}, \mathrm{n}=5$ rats.

Different superscript letters within the same column indicate significant differences at $p<0.05$.

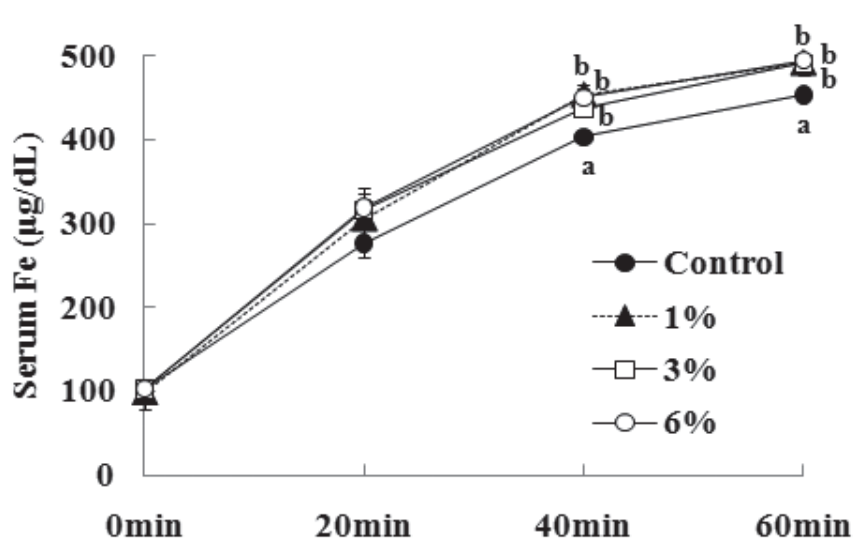

Fig. 1. Effect of various concentrations of citric acid (1-6\%) on serum iron levels with administration of ferric iron by gavage dose of $2 \mathrm{mg} \mathrm{Fe}^{3+} / \mathrm{kg}$. Serum iron was measured at 0, 20, 40 and $60 \mathrm{~min}$ after the administration.

Values are means \pm SEM, $\mathrm{n}=8$ rats.

Different letters indicate significant differences at $p<0.05$.

control group. Serum iron level was significantly higher in the citric acid group and basal diet group than in the control group. Hemoglobin concentration was significantly higher in the citric acid group and lemon juice group than in the control group, but the concentration in the basal diet group was significantly higher than in the other four groups. Hematocrit value was significantly higher in the citric acid group than in the control group, but the value in the basal diet group was significantly higher than in the other four groups. The lemon juice group showed a tendency to improve the hematocrit value, but there were no significant differences between the lemon juice group and control group. The $\mathrm{HCl}$ group showed a tendency to improve the hemoglobin concentration and hematocrit value, but there were no significant differences between the $\mathrm{HCl}$ group and control group.

\section{Discussion}

Iron uptake from the small intestine is enhanced by the iron deficiency state (Huebers et al., 1990), so iron absorption in the iron-deficient rat was compared with that in the normal rat to better observe the kinetics of iron uptake. Accordingly, in Expt. 1, we investigated the effect of citric acid on the absorption of ferric iron in iron-deficient rats.

In this study, the absorption of ferric iron was promoted by the presence of citric acid in iron-deficient rats. The effect of citric acid on ferric iron absorption may be due to its ability to chelate with ferric ions which produces the more soluble forms in the small intestine. Solubility of nonheme iron in the small intestine is a major factor in determining its absorption. Salovaara et al. (2003) suggested that organic acids promoted uptake of ferric iron by chelation and by lowering the $\mathrm{pH}$ in vitro. Hungerford and Linder (1983) showed that the $\mathrm{pH}$ is elevated rapidly in the small intestine, whereby iron solubility is lowered, but in the presence of a chelating agent such as ascorbic acid, the iron continues to be available for absorption, due to the capacity of ascorbic acid to maintain iron in a water-soluble, bioavailable form. As citric acid is also a chelating agent, the administration of ferric iron with citric acid in this study might have increased serum iron levels by the same mechanisms as described above.

On the other hand, Ujike et al. showed that the administrations of iron with $0.3-1.9 \%$ rice vinegar increased serum iron levels in a dose-independent manner, and they suggested that the effect of vinegar on iron absorption is attributable to a promoting effect of acetic acid in vinegar on gastric acid secretion. Similar results were obtained with the administrations of iron with $1-6 \%$ citric acid in this study, since the enhancing effect of citric acid on iron absorption might be due to an efficacy in promoting gastric acid secretion. However, a dose-dependent manner may be observed at a smaller dose of citric acid.

Subsequently, in Expt. 2, we investigated the effects of repeated administrations of ferric iron with citric acid or lemon juice on anemic rats. Feeding with the F2FeDD diet for $28 \mathrm{~d}$ induced anemia because it decreased hemoglobin concentration below $8 \mathrm{~g} / \mathrm{dL}$ (Campos et al., 1998), and then the repeated administrations of ferric iron with citric acid improved anemia, thereby preventing heart hypertrophy, de- 
creasing UIBC, and increasing serum iron level, hemoglobin concentration and hematocrit value. Although the hemoglobin concentration increased with the addition of lemon juice, the improving effect of citric acid on anemia seemed to be higher than that of the diluted lemon juice in this study. Lemon juice contains also polyphenols and fiber (Sinclair, 1984; Miyake et al., 2007), and these components act as inhibitors of nonheme iron absorption (Sean and Lynch, 1997; Bothwell et al., 1989). Therefore, the effects of these inhibitors might outweigh those of the citric acid in the diluted lemon juice.

To confirm the effects of $\mathrm{pH}$ of the solutions on the absorption of ferric iron and the improvement of anemia, we prepared the $\mathrm{HCl}$ group. The $\mathrm{HCl}$ group showed a tendency to improve anemia, but there were no significant differences. Consequently, we think that the effect of low $\mathrm{pH}$ of the solutions on the bioavailability of ferric iron observed in this study is relatively weak.

In conclusion, these results suggest that ingestion of citric acid or lemon juice enhances nonheme iron absorption and improves anemia by chelating and stabilizing ferric iron in vivo.

\section{References}

Ballot, D., Baynes, R.D., Bothwell, T.H., Gillooly, M., MacFarlane, B.J., MacPhail, A.P., Lyons, G., Derman, D.P., Bezwoda, W.R., Torrance, J.D. and Bothwell, J.E. (1987). The effects of fruit juices and fruits on the absorption of iron from a rice meal. $\mathrm{Br} . J$. Nutr., 57, 331-343.

Beale, R.N., Bostrom, J.O. and Taylor, R.F. (1962). Improved rapid methods for the determination of iron content and binding capacity of serum. J. Clin. Pathol., 15, 156-160.

Bothwell, T.H., Baynes, R.D., MacFarlane, B.J. and MacPhail, A.P. (1989). Nutritional iron requirements and food iron absorption. $J$. Intern. Med., 226, 357-365.

Campos M.S., Barrionuevo M., Alférez M.J., Gómez-Ayala A.E., Rodríguez-Matas M.C., Lopez Aliaga I. and Lisbona F. (1998). Interactions among iron, calcium, phosphorus and magnesium in the nutritionally iron-deficient rat. Exp. Physiol., 83, 771-781.

Derman, D.P., Bothwell, T.H., Torrance, J.D., Bezwoda. W.R., MacPhail, A.P., Kew, M.C., Sayers, M.H., Disler, P.B. and Charlton, R.W. (1980). Iron absorption from maize (Zea mays) and sorghum (Sorghum vulgare) beer. Br. J. Nutr., 43, 271-279.

Garcia, O.P., Diaz, M., Rosado, J.L. and Allen, L.H. (2003). Ascorbic acid from lime juice does not improve the iron status of irondeficient women in rural Mexico. Am. J. Clin. Nutr., 78, 267-273.
Gillooly, M., Bothwell, T.H., Torrance, J.D., MacPhail, A.P., Derman, D.P., Bezwoda, W.R., Mills, W., Charlton, R.W. and Mayet, F. (1983). The effects of organic acids, phytates and polyphenols on the absorption of iron from vegetables. Br. J. Nutr., 49, 331342 .

Huebers, H.A., Csiba, E., Josephson, B. and Finch, C.A. (1990). Iron absorption in the iron-deficient rat. Blut., 60, 345-351.

Hungerford, D.M. Jr. and Linder, M.C. (1983). Interactions of $\mathrm{pH}$ and ascorbate in intestinal iron absorption. J. Nutr., 113, 26152622.

Kawakami, H., Hiratsuka, M. and Dosako, S. (1988). Effects of iron-saturated lactoferrin on iron absorption. Agric. Biol. Chem., 52, 903-908.

Katsumata, S., Tsuboi, R., Uehara, M. and Suzuki, K. (2006). Dietary iron deficiency decreases serum osteocalcin concentration and bone mineral density in rats. Biosci. Biotechnol. Biochem., 70, 2547-2550.

Miyake, Y., Mochizuki, M., Okada, M., Hiramitsu, M., Morimitsu, Y. and Osawa, T. (2007). Isolation of antioxidative phenolic glucosides from lemon juice and their suppressive effect on the expression of blood adhesion molecules. Biosci. Biotechnol. Biochem., 71, 1911-1919.

Ndong, M., Uehara, M., Katsumata, S., Sato, S. and Suzuki, K. (2007). Preventive effects of Moringa oleifera (Lam) on hyperlipidemia and hepatocyte ultrastructural changes in iron deficien rats. Biosci. Biotechnol. Biochem., 71, 1826-1833.

Salovaara, S., Sandberg, A.S. and Andlid, T. (2003). Combined impact of $\mathrm{pH}$ and organic acids on iron uptake by Caco-2 cells. $J$. Agric. Food Chem., 51, 7820-7824.

Sean, R. and Lynch, M.D. (1997). Interaction of Iron with Other Nutrients. Nutr. Rev., 55, 102-110.

Sinclair, W.B. (1984). Some soluble and insoluble constituents of citrus fruits. In "The Biochemistry and Physiology of the Lemon and Other Citrus Fruits", Division of Agriculture and Natural Resource, University of California, Oakland, pp. 79-82.

Stoltzfus, R.J. and Dreyfuss, M.L. (1998). Guidelines for the use of iron supplements to prevent and treat iron deficiency anemia. International Life Sciences Institute Press, Washington, DC.

Ujike, S., Shimoji Y., Nishikawa, Y., Taniguchi, M., Nanda, K., Ito, R., Kawabata, D. and Uenakai, K. (2003). Effect of vinegar on absorption of iron in rats. J. Jpn. Soc. Nutr. Food Sci., 56, 371374 (in Japanese with English abstract).

Zhang, H., Onning, G., Oste, R., Gramatkovski, E. and Hulthén, L. (2007). Improved iron bioavailability in an oat-based beverage: the combined effect of citric acid addition, dephytinization and iron supplementation. Eur. J. Nutr., 46, 95-102. 